\title{
Reactive Crystallization of Calcium Oxalate: Population Balance Modeling
}

\author{
K. Rewatkar, D. Z. Shende, " and K. L. Wasewar \\ Advance Separation and Analytical Laboratory, \\ Department of Chemical Engineering, \\ Visvesvaraya National Institute of Technology, \\ Nagpur - 440010 India
}

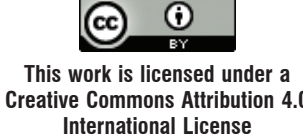

International License

doi: 10.15255/CABEQ.2016.953

Original scientific paper

Received: July 20, 2016

Accepted: February 8, 2018

Reactive crystallization of calcium oxalate has been studied to determine particle size distribution for calcium oxalate precipitation using population balance model with method of moments. The model is formulated and tested for single feed semi-batch reactive crystallization of calcium oxalate with reactants calcium chloride and sodium oxalate with literature data. The simulated results include local supersaturation distribution, number of particle distribution, mass of particle crystallized, particle size, nucleation and growth rate during the process. The model results are in good agreement with available experimental data from literature.

Keywords:

reactive crystallization, population balance model, method of moments, calcium oxalate

\section{Introduction}

Reactive crystallization is widely used in the production of fine chemicals, pigments, catalysts, ceramics, food stuffs, etc., and especially in the pharmaceutical industry. Recent applications include crystalline materials for electronic chemicals, specialty applications such as healthcare products, agriculture, photography chemicals, etc. ${ }^{1,2}$ One of the important challenges in the field of industrial crystallization is to match the changing and growing product requirements by controlling the crystal morphology, size distribution, and polymorphism. The effects and side effects of drugs depend upon crystal size, shape, and dissolution rate. Performance of consumer products strongly depends on the understanding of crystallization process. Crystals of cocoa in chocolate decide its taste. Crystal size controls the texture in ice creams, and free flowing nature of salt and sugar. ${ }^{3}$

Calcium oxalate is gaining a lot of attention by researchers from a medical point of view, as it is a major inorganic constituent of urinary calculi, and majorly contributes to the formation of kidney stones. In India, approximately 5-7 million patients are suffering from kidney stone disease. Urinary oxalate is found to be a major factor for $\mathrm{CaOx}$ stone formation. As the molar ratio of oxalate-to-calcium is normally $1: 10$, slight changes in urinary oxalate concentration may cause crystallization and stone

"Corresponding author: diwakar.shende@gmail.com; Tel.: +91-712-2801567; Fax: +91-712-2223969 formation as compared to calcium concentration. ${ }^{4}$ It has been investigated that during the process of water conservation in the body, the kidney supersaturates urine. Supersaturation being a driving force may cause crystal formation of $\mathrm{CaOx}$. If inhibitors of crystal formation like protein, citrate, etc., in the body are unable to take proper action and control their size, it may end up with nephrolithiasis, a recurrent disease which has been found to be associated with an increased risk of hypertension, coronary artery disease, diabetes, and metabolic syndrome. ${ }^{5}$ Hence, formation of kidney stones is a complex process which involves several factors. In urine, nucleation and growth of $\mathrm{CaOx}$ crystals are affected by the level of supersaturation due to calcium and oxalate ions by a variety of urinary components. Therefore, detailed knowledge on the formation of kidney stones and its mechanism would be helpful and contributing in the prevention of the disease and the search for its remedies.

Reactive crystallization of $\mathrm{CaOx}$ has been investigated by various research groups. ${ }^{6-11}$ Semibatch crystallization is widely used in the chemical industry for manufacturing of various chemicals in many operational modes due to its simplicity, flexibility, less investment and easy process development. It controls the level of supersaturation by providing various operating modes and contacting patterns like the feed tube can be placed on the solution surface or in the bulk solution or near the impeller. In semi-batch mode, both solvent capacity and solute concentration can be manipulated independently with time for a given system. ${ }^{12}$ Therefore, 
in the present study, the reactive crystallization of calcium oxalate is preferred in semi-batch operation.

\section{Theory}

The mathematical framework used to describe the nucleation, growth, agglomeration or breakage is called the population balance. The population balance equation (PBE) was introduced by Hulburt and $\mathrm{Katz}^{13}$ and developed by Randolph and Larson ${ }^{14}$ to describe the particle size and number distribution in various chemical engineering systems, such as crystallization, liquid-liquid/liquid-gas dispersion, biological process, microbial cultures, granulation, grinding, polymerization, bubble columns aerosol reactors, etc. ${ }^{15-17}$ It is a non-linear hyperbolic integro-partial differential equation, which involves all the crystallization kinetic phenomena. Ramkrishna explained in detail the population balance. ${ }^{18,19}$ Many researchers have used the population balance for modelling, simulating, controlling, and analysing the crystallization process..$^{20,21}$ Recently, Barrasso et $a l^{22}$ used population balance to predict CQAs (critical quality attributes) in pharmaceutical drug manufacturing.

Different solution techniques for PBE are reviewed in the literature, which includes method of moments (MOM) ${ }^{13}$ weighted residuals/orthogonal collocation method, ${ }^{19}$ finite difference method/discretized population balance, ${ }^{23}$ Method of Classes, ${ }^{24}$ Method of Characteristics, ${ }^{14}$ and Monte Carlo method..$^{25}$ The method of moments (MOM) is one of the most common methods in solving population balance equations (PBEs). PBE can be easily transformed into a set of ordinary differential equations (ODEs) and only a small number of ODEs need to be solved. It reduces the dimensionality of the problem to make it simpler. MOM cannot be applied for gas-liquid systems, which involves bubble breakage and coalescence as a major factor. ${ }^{14}$

In the present work, a mathematical model was developed to simulate the semi-batch reactive crystallization of calcium oxalate, which is a major component of human kidney stones. The majority of the product properties, like particle size and shape are affected by nucleation and growth mechanism, which could be pre-fixed by a controlled process. The effect of process parameters, such as feed rate, initial reactant concentration, initial supersaturation, feed time on final particle size, and crystal yield of calcium oxalate during the process have been investigated. The simulated results include distribution of the local supersaturation ratio in the reactor, mean crystal size, moments $(0,1,2$, $3,4)$ distribution, concentration of crystals precipitated. In this paper, the focus is given on the interplay of nucleation, crystal growth, and particle size distribution.

\section{Process description}

The present paper focuses on single feed semibatch reactive crystallization of calcium oxalate. Equimolar calcium chloride and sodium oxalate $(\mathrm{NaOx})$ have been considered to precipitate calcium oxalate $(\mathrm{CaOx})$ with volume ratio (feed volume to reactor volume) of 0.2 . Initially, $200 \mathrm{~mL} \mathrm{NaOx}$ solution of concentration $0.008 \mathrm{kmol} \mathrm{m}^{-3}$ was taken in the vessel and total $200 \mathrm{~mL} \mathrm{CaCl}_{2}$ solution of the same molarity was added continuously with the help of peristaltic pump within $40 \mathrm{~min}$ to the vessel. A one-litre reactor volume was considered. ${ }^{26}$ Process conditions were considered as mentioned by Zauner et al. ${ }^{26}$ for the reactive precipitation of calcium oxalate. The performance of the system was studied by varying the concentration of $\mathrm{CaCl}_{2}$ and $\mathrm{NaOx}$ in the range from $0.004-0.02 \mathrm{kmol} \mathrm{m}^{-3}$, the volume feed rate of $\mathrm{CaCl}_{2}$ from $3.33-20 \mathrm{~mL} \mathrm{~min}^{-1}$, and the reaction time from 600-3600 s. The kinetic parameters and the physical properties for $\mathrm{CaOx}$ precipitation system used in the simulation are presented in Table 1, and the schematic view of studied process system is shown in Fig. 1.

\section{Model development}

The instantaneous chemical reaction for precipitation of calcium oxalate ${ }^{26}$ can be represented as:

$$
\begin{aligned}
& \mathrm{CaCl}_{2}+\mathrm{Na}_{2} \mathrm{C}_{2} \mathrm{O}_{4} \rightarrow \mathrm{CaC}_{2} \mathrm{O}_{4} \downarrow+2 \mathrm{NaCl} \\
& \mathrm{NaOx} \quad \mathrm{CaOx}
\end{aligned}
$$

Calcium oxalate $(\mathrm{CaOx})$ precipitates as a solid product due to its concentration exceeding the solubility limit.

Table 1 - Kinetic parameters and physical properties used in simulations with PBM for single feed semi-batch

\begin{tabular}{|c|c|c|}
\hline Property & Unit & Values \\
\hline Kinetic parameter, $B^{0}$ & number $\mathrm{m}^{-3} \mathrm{~s}^{-1}$ & $9.38 \cdot 10^{11}$ \\
\hline Thermodynamic constant, $A_{p}$ & - & 52.09 \\
\hline Growth rate constant, $k_{g}$ & $\mathrm{~m} \mathrm{~s}^{-1}$ & $5.9 \cdot 10^{-10}$ \\
\hline Exponential for growth rate, $g$ & - & 2 \\
\hline Solubility product, $K_{s p}$ & $\left(\mathrm{kmol} \mathrm{m}^{-3}\right)^{2}$ & $2.51 \cdot 10^{-9}$ \\
\hline Volumetric shape factor, $k_{v}$ & - & 0.45 \\
\hline Molecular weight, $\mathrm{CaOx}, M_{C}$ & $\mathrm{~kg} \mathrm{kmol}^{-1}$ & 146.1 \\
\hline Density, $\mathrm{CaOx}, \rho_{C}$ & $\mathrm{~kg} \mathrm{~m}^{-3}$ & 2200 \\
\hline Molecular weight, $\mathrm{NaOx}, M_{A}$ & $\mathrm{~kg} \mathrm{kmol}^{-1}$ & 134 \\
\hline Density, $\mathrm{NaOx}, \rho_{A}$ & $\mathrm{~kg} \mathrm{~m}^{-3}$ & 2340 \\
\hline Molecular weight, $\mathrm{CaCl}_{2}, M_{B}$ & $\mathrm{~kg} \mathrm{kmol}^{-1}$ & 111 \\
\hline Density, $\mathrm{CaCl}_{2}, \rho_{B}$ & $\mathrm{~kg} \mathrm{~m}^{-3}$ & 2150 \\
\hline
\end{tabular}
precipitation of calcium oxalate 


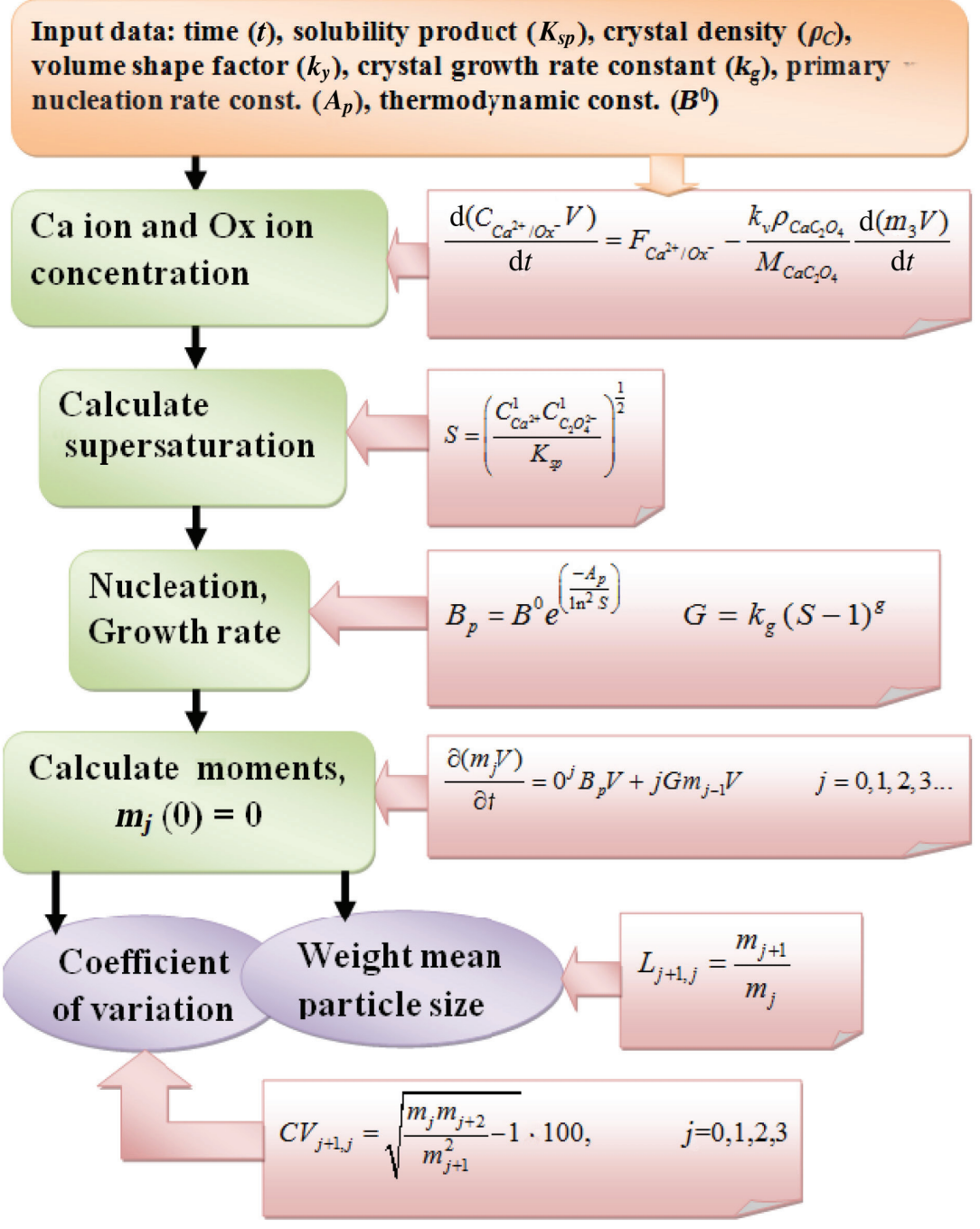

Fig. 1 - Schematic view of studied process system

\section{Material balance}

For semi-batch reactor, the capacity of the reactor, $V$, in terms of $\mathrm{kg}$ solvent, varies with time. Variation of solvent capacity in the crystallizer is given as:

$$
\frac{\mathrm{d} V}{\mathrm{~d} t}=\dot{m}_{\mathrm{CaCl}_{2}}+\dot{m}_{\mathrm{NaOx}}
$$

where $\dot{m}_{\mathrm{CaCl}_{2}}$ is the mass flow rate ( $\mathrm{kg}$ solvent s $\mathrm{s}^{-1}$ ) of calcium chloride stream. For single feed semibatch reaction system $\dot{m}_{N a O x}=0$.

The concentrations of cations, anions, and the crystals precipitated during the formation of calcium oxalate can be defined $\mathrm{as}^{27}$ :

$$
\begin{gathered}
\frac{\mathrm{d}\left(C_{C a O x} V\right)}{\mathrm{d} t}=\frac{k_{v} \rho_{C a O x}}{M_{C a O x}} \frac{\mathrm{d}\left(m_{3} V\right)}{\mathrm{d} t} \\
\frac{\mathrm{d}\left(C_{\mathrm{Ca}^{2+}} V\right)}{\mathrm{d} t}=F_{C a^{2+}}-\frac{k_{v} \rho_{\mathrm{CaOx}}}{M_{C a O x}} \frac{\mathrm{d}\left(m_{3} V\right)}{\mathrm{d} t} \\
\frac{\mathrm{d}\left(C_{O x^{2}} V\right)}{\mathrm{d} t}=\frac{k_{v} \rho_{C a O x}}{M_{C a O x}} \frac{\mathrm{d}\left(m_{3} V\right)}{\mathrm{d} t}
\end{gathered}
$$

where $C_{\mathrm{CaOx}^{2}}, C_{\mathrm{Ca}^{2+}}, C_{\mathrm{Ox}^{2-}}$ are the concentrations of calcium oxalate crystals, calcium ions, and the oxalate ions, respectively. $F$ is the molar feed rate of solute $\left(\mathrm{kmol}\right.$ solute $\left.\mathrm{s}^{-1}\right) \cdot m_{\mathrm{j}}$ is the $\mathrm{j}^{\text {th }}$ moment $(\mathrm{j}=$ $0,1,2,3 \ldots)$ for crystal size distribution $\left(\mathrm{m}^{\mathrm{j}} / \mathrm{kg}\right.$ solvent). Eq. (3), (4) and (5) can be used to calculate the concentrations of precipitated crystals, cations, and anions, respectively. The third moment of crystal size distribution $\left(m_{3}\right)$ is needed, which depends on the values of the second, first and zeroth moments $\left(m_{2}, m_{1}, m_{0}\right)$ consequently. The population balance equation (PBE) was solved to calculate the moments using method of moments (MOM).

\section{Population balance modeling}

The population balance equation (PBE) can be simplified for semi-batch reactor by assuming absence of particle breakage, agglomeration, secondary nucleation or aging, zero size nuclei formation, size-independent growth rate, crystal-free feed and perfectly mixed semi-batch reactor as: 


$$
\frac{\partial n}{\partial t}+G \frac{\partial n}{\partial L}+\frac{n}{V} \frac{\partial V}{\partial t}=0
$$

where, $n$ is number density function, $G$ is growth rate $\left(\mathrm{m} \mathrm{s}^{-1}\right)$, and $L$ is crystal size $(\mu \mathrm{m})$.

$\partial n / \partial t$ is change in number density with respect to time in semi-batch crystallizer.

$\partial n / \partial L$ is difference between the crystal growing into and out of a crystal size interval $\mathrm{d} L$.

$\partial V / \partial t$ is changes in crystal volume with respect to time.

The PBE for semi-batch reaction system, Eq. (6) can be solved using method of moments (MOM) by converting it into ordinary differential equations (ODEs) (Eqs. 9-13).

\section{Method of moments (MOM)}

To avoid complexity of PBE, a simplified MOM was used to obtain the particle size distribution and moments by solving PBE, where the moment can be defined as ${ }^{14}$ :

$$
\begin{aligned}
& m_{j}=\int_{0}^{\infty} L^{j}\left[\frac{\partial n}{\partial t}+G \frac{\partial n}{\partial L}+\frac{n}{V} \frac{\partial V}{\partial t}\right] d L=0 \\
& j=0,1,2,3 \ldots . .
\end{aligned}
$$

The number, length, surface area, volume, and mass of crystals can be expressed in terms of the moments. Moments from 0 to 3 have physical meanings. The moments of distributions $m_{0}, m_{1}, m_{2}$, $m_{3}$ can be obtained by solving the following set of non-linear ordinary differential equations.

$$
\frac{\mathrm{d}\left(m_{0} V\right)}{\mathrm{d} t}=B_{p} V
$$

where $B_{p}$ is the primary nucleation rate (number $\mathrm{kg}^{-1}$ solvent $\mathrm{S}^{-1}$ ). The nucleation rate is discussed in detail in Eq. (17) in the Result and discussion section. The zeroth moment, $m_{0}$, signifies the total number of crystals per unit volume of suspension.

$$
\frac{\mathrm{d}\left(m_{1} V\right)}{\mathrm{d} t}=m_{0} G V
$$

where $G$ is the growth rate $\left(\mathrm{m} \mathrm{s}^{-1}\right)$. The growth rate has been described in detail in Eq. (19). First moment, $m_{1}$, is the total length of crystals per unit volume of suspension, laid end-to-end along the axis.

$$
\frac{\mathrm{d}\left(m_{2} V\right)}{\mathrm{d} t}=2 m_{1} G V
$$

where, $m_{2}$ is the second moment, indicates the total surface area of all crystals per unit volume of suspension.

$$
\frac{\mathrm{d}\left(m_{3} V\right)}{\mathrm{d} t}=3 m_{2} G V
$$

where, the third moment, $m_{3}$, signifies the total crystal volume per unit volume of suspension.

$$
\frac{\mathrm{d}\left(m_{4} V\right)}{\mathrm{d} t}=4 m_{3} G V
$$

The initial conditions used to solve the above equations are:

$$
\text { At } t=0, \quad m_{j}(0)=0 \quad j=0,1,2,3,4 \ldots \ldots
$$

The performance of the reactive precipitation is normally assessed in terms of CSD, which is presented in terms of average crystal size. The particle size can be calculated using the crystal size distribution moments as:

$$
L_{4,3}=\frac{m_{4}}{m_{3}}
$$

where $L_{4,3}$ is the volume or weight mean size.

\section{Results and discussion}

In order to develop a model for single feed semi-batch reactive crystallization process, knowledge of particle size, coefficient of variation, mass of the crystal precipitated are necessary. A forward difference scheme by developing macros in Microsoft Excel 2007 was used to solve the model equations. The influence of two parameters, feed rate, and feed concentrations, are discussed.

Supersaturation plays a key role in the reactive crystallization process. The rate of crystallization is decided by the level of supersaturation. More efficiently and accurately controlled supersaturation leads to better control over nucleation and growth, hence the rate of the precipitation process. Supersaturation is the temporary rise in solute concentration in solvent above its equilibrium.

Dissociated anions and cations in the electrolytic solution of calcium oxalate $(\mathrm{CaOx})$ precipitate are responsible for crystal formation. Supersaturation ratio for ionic reactions can be defined as:

$$
\begin{gathered}
\mathrm{CaC}_{2} \mathrm{O}_{4} \rightleftarrows \mathrm{Ca}^{2+}+\mathrm{C}_{2} \mathrm{O}_{4}^{2-} \\
S=\left(\frac{C_{\mathrm{Ca}^{2+}}^{1} C_{\mathrm{C}_{2} \mathrm{O}_{4}^{2-}}^{1}}{K_{s p}}\right)^{\frac{1}{(1+1)}}
\end{gathered}
$$

where $K_{s p}$ is solubility product, $C_{\mathrm{Ca}^{2+}}$ and $C_{\mathrm{C}_{2} \mathrm{O}_{4}^{2-}}$ are the concentrations of the cations and anions that are available in the solution. After achieving the supersaturation, the system tries to reach solubility limit through nucleation and growth.

Fig. 2 reveals the trajectories for supersaturation during the course of reaction in the vessel corresponding to various feed concentrations for a con- 


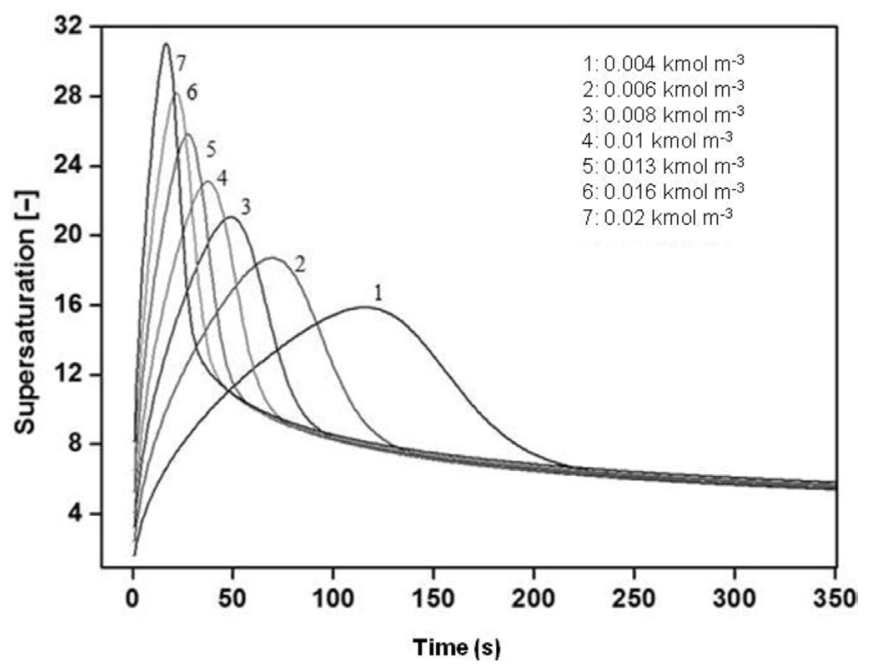

Fig. 2 - Local supersaturation distribution during process of semi-batch reactive crystallization of calcium oxalate at $5 \mathrm{~mL} \mathrm{~min}^{-1}$

stant feed addition $\left(5 \mathrm{~mL} \mathrm{~min}^{-1}\right)$. It may be pointed out that the higher concentration leads to an early increase in supersaturation. However, this early supersaturation peak is necessary in order to produce required crystals for successive growth. The higher feed concentration of calcium chloride and sodium oxalate causes the increase in supersaturation during the process due to more contribution of the oxalate ions.

Primary homogeneous nucleation is the formation of nucleus in a solution containing no foreign particles or no crystals of the same material. The nucleation rate for homogeneous primary nucleation can be defined as $^{28}$ :

$$
B_{p}=B^{0} e^{\left(\frac{-A_{p}}{\ln ^{2} S}\right)}
$$

where $S$ is supersaturation ratio (unitless), $B^{0}$ is kinetic parameter (number $\mathrm{m}^{-3} \mathrm{~s}^{-1}$ ) and $A_{p}$ is the thermodynamic constant (unitless).

$$
A_{p}=\frac{16 \pi \gamma^{3} v^{2}}{3(k T)^{3}}
$$

$\gamma$ is interfacial tension $\left(\mathrm{J} \mathrm{m}^{-2}\right), v$ molecular volume $\left(\mathrm{m}^{3}\right), k$ Boltzmann's constant $\left(1.3805 \cdot 10^{-23} \mathrm{~J} \mathrm{~K}^{-1}\right)$, $T$ solution temperature $(\mathrm{K})$. Primary homogeneous nucleation is highly non-linear and occurs spontaneously. From Eq. (18), it is clear that the value of primary nucleation is very low for small values of supersaturation, but becomes very high beyond critical supersaturation. Critical supersaturation is the maximum supersaturation level that a metastable old phase can last without nucleation, and above which nucleation will occur instantly. ${ }^{28}$ Primary nucleation begins when supersaturation reaches the level of critical supersaturation. In reactive crystallization, rapid reaction creates very high local su- persaturation, which can significantly exceed critical supersaturation and result in very high, local primary nucleation. Fig. 3 reveals that a large number of particles are produced due to increased supersaturation and the higher nucleation rate. The similar kind of trend has been observed by Alatalo, Michel et al., Blandin et al. ${ }^{29-31}$ during reactive crystallization of L-glutamic acid, calcium oxalate, and salicylic acid, respectively.

Nucleus, after reaching the critical size, begins to grow. It is the time rate of change of characteristic dimension $L$ of the crystal. ${ }^{28}$

$$
G=\frac{\mathrm{d} L}{\mathrm{~d} t}=k_{g}(S-1)^{g}
$$

where, $g$ is the exponent to growth rate. The value of $g$ is usually in the range ${ }^{32}$ between 0 and 2.5. For precipitating systems, many studies have shown second order dependence of growth rate on supersaturation in the form of the parabolic growth law, ${ }^{33}$ i.e., $g=2$. Nucleation and growth are dependent on supersaturation ratio $S$.

Fig. 4 shows a plot of growth rate versus process time. The calculated growth rate for calcium oxalate is in the range of $5.5 \cdot 10^{-7}$ to $1 \cdot 10^{-7} \mathrm{~m} \mathrm{~s}^{-1}$ for 1-litre reactor with feed rate $5-20 \mathrm{~mL} \mathrm{~min}^{-1}$ and with molar feed concentration 0.004-0.02 M. Literature shows various values for growth rate ${ }^{30}$ of calcium oxalate monohydrate, varying from $5 \cdot 10^{-8}$ to $4.5 \cdot 10^{-7} \mathrm{~m} \mathrm{~s}^{-1}$. The values obtained by simulations are therefore within range of literature data. A similar growth profile was shown by Grohe et al. ${ }^{4}$ using scanning confocal interference microscopy during analysis of $\mathrm{CaOx}$ precipitation.

The total number of crystals increases greatly with initial supersaturation, hence nucleation is sen-

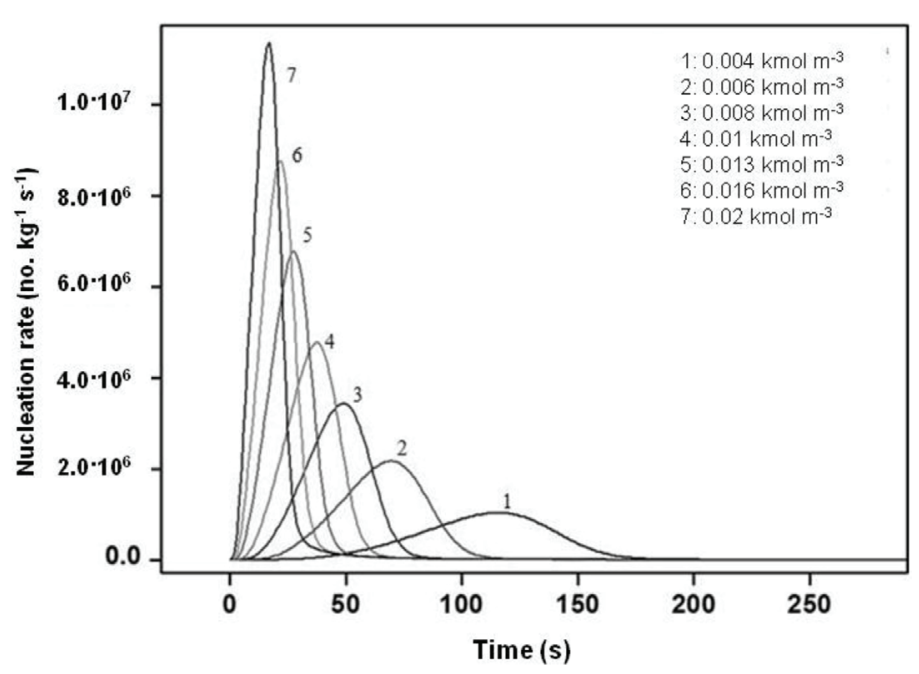

Fig. 3 - Nucleation rate simulated with PBM for initial concentration of reactants $\mathrm{CaCl}$ and $\mathrm{NaOx}$ varied from 0.004 to $0.02 \mathrm{kmol} \mathrm{m}^{-3}$ in single feed semi-batch crystallizer with feed rate of $5 \mathrm{~mL} \mathrm{~min}^{-1}$ 


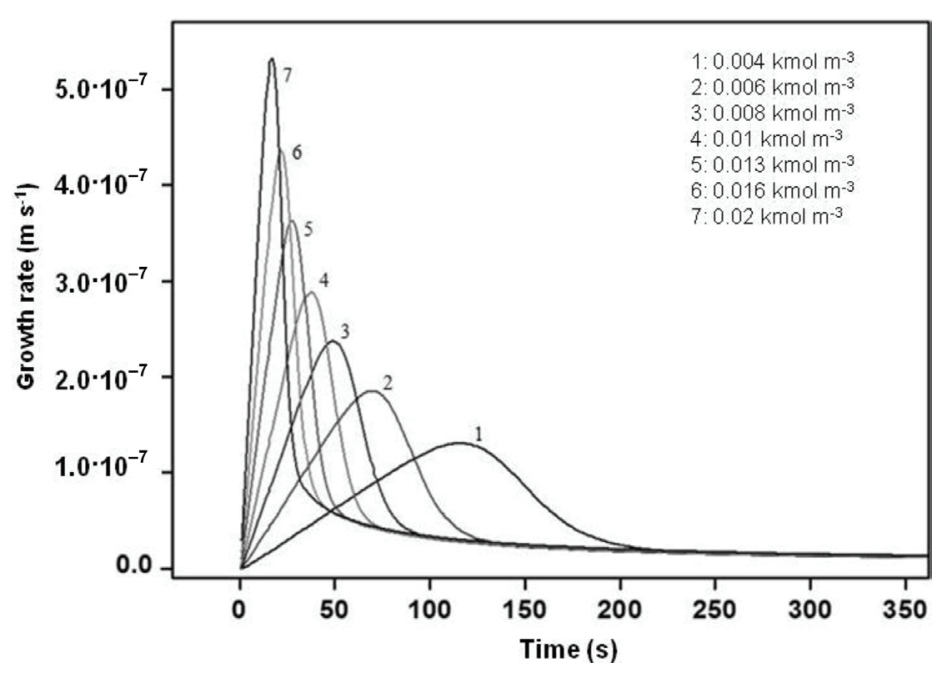

Fig. 4 - Effect of concentration on growth rate during process of semi-batch reactive crystallization of calcium oxalate at $5 \mathrm{~mL} \mathrm{~min}^{-1}$ feed rate

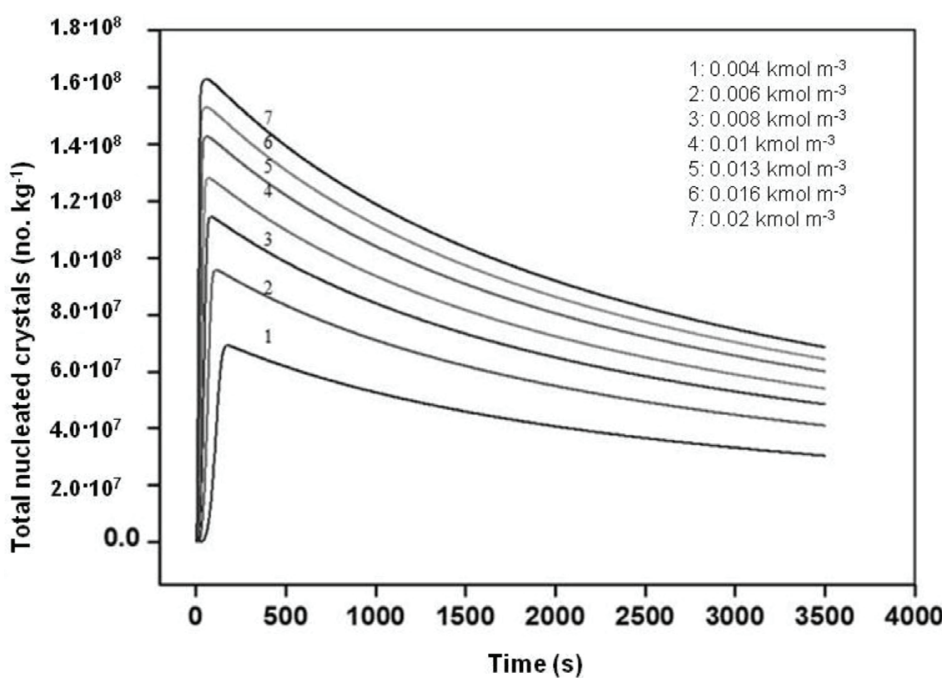

Fig. 5 - Effect of concentration of reactants on total crystals nucleated at $5 \mathrm{~mL} \mathrm{~min}^{-1}$ feed rate

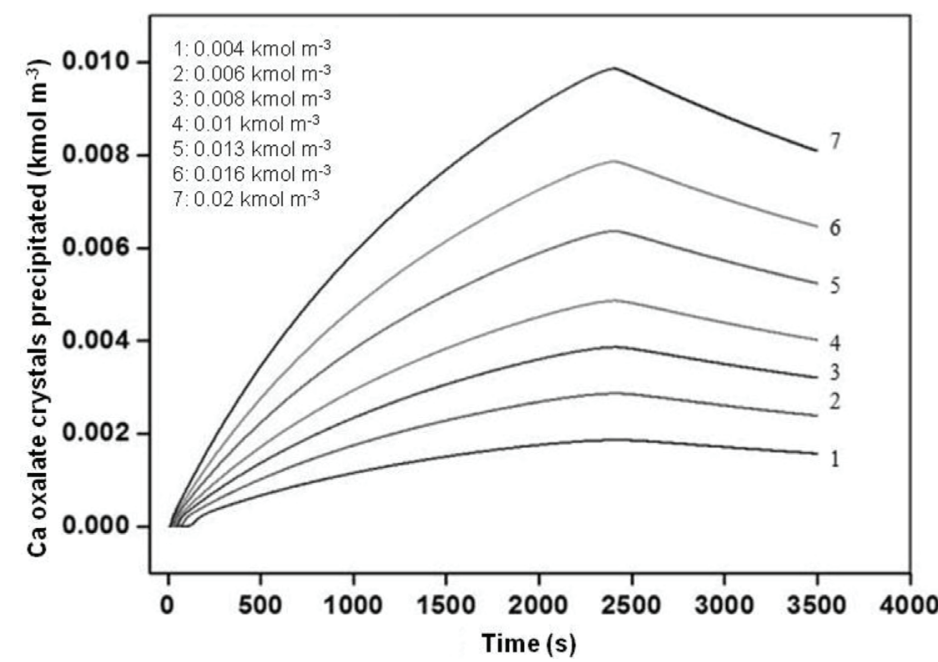

Fig. 6-Model prediction of product crystals precipitated with different initial concentrations of reactants during process at $5 \mathrm{~mL} \mathrm{~min}^{-1}$ feed rate sitive to supersaturation. The supersaturation varies with the rate of addition of reactant feed. In Fig. 4, total number of particles is plotted against residence

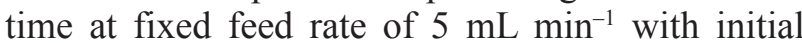
concentration varying in the range from 0.004 to $0.02 \mathrm{kmol} \mathrm{m}^{-3}$. The same trend was observed by Aamir et $a .^{34}$ for potash alum. The plot indicates that the number of particles reduces with time due to agglomeration. Initial supersaturation peak (Fig. 2) shows high crystal growth rate (Fig. 4) as compared to later supersaturation, corresponding to lower concentration. However, the crystals produced near the end of supersaturation peak do not get a chance to attain the high growth rate, and show sudden decrease in the growth rate due to abrupt reduction in level of supersaturation.

Fig. 5 illustrates that the constant feed rate causes nucleation of all the crystals in the beginning of the operation. Fig. 6 shows that the amount of the precipitated crystals increases with increase in initial concentration of the reactant during the reaction. However, there is a decrease in the concentration of precipitated crystals towards the end of the process due to Ostwald ripening. Fig. 7 shows that the particle size decreases with the increased feed rate due to rise in initial supersaturation, which increases with feed rate and initial reactant concentration. The same observation has been experimentally investigated by Baldyga et al. ${ }^{35}$ for barium sulphate, and by Lindenberg and Mazzotti ${ }^{36}$ for L-asparagine monohydrate crystals. Hence, it can be concluded that the particle size can be controlled by adjusting the initial supersaturation.

The particle size obtained by model equations was compared with the experimental data for semibatch reactive crystallization of calcium oxalate for similar process conditions. The obtained model results were found in good agreement with experimental data. The weight mean particle size $\left(L_{4,3}\right)$ was observed to be $25 \mu \mathrm{m}$ experimentally ${ }^{26}$ and the predicted particle size by population balance model was found to be $22.2 \mu \mathrm{m}$, which is in good agreement with the experimental value. Thus, the developed model was validated.

\section{Conclusion}

In the present study, Method of moments was used to explore population balance modeling to determine the particle size of calcium oxalate in semibatch reactive crystallization. The model equations were solved using forward difference scheme by developing macros in Microsoft Excel 2007. Model results are in close agreement with experimental values from literature. 


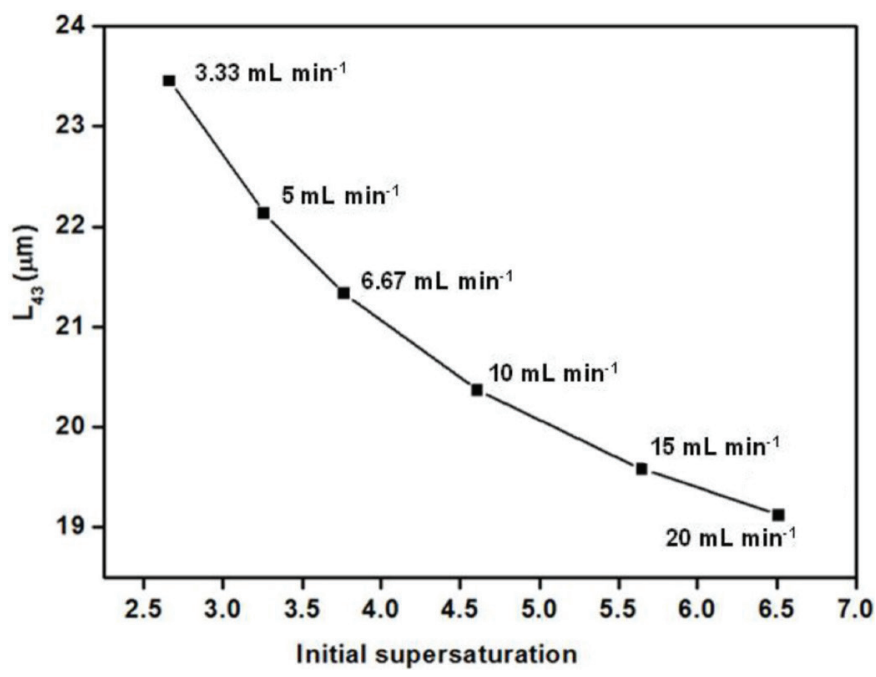

Fig. 7 - Variation of particle size with initial supersaturation at fixed initial feed concentration $(0.008 \mathrm{M})$ during process of semi-batch reactive crystallization of calcium oxalate

The effects of feed rate $\left(3.33-20 \mathrm{~mL} \mathrm{~min}^{-1}\right)$ and concentration $\left(0.004-0.02 \mathrm{kmol} \mathrm{m}^{-3}\right)$ were studied, and it was found that number concentration increases with supersaturation. The feed rate controls the level of supersaturation. A high reactant feed rate is required to attain a high initial supersaturation, which is needed to produce particles of smaller size. It is concluded that high supersaturation leads to higher nucleation with large number of particles. The effect of various operating parameters was studied by applying the population balance model, and found that the model reproduces the literature results successfully. The data generated using the model helps to analyse process variable impact on particle size, and guess the starting point for experimental work. The developed model can be used to find out the optimal operating conditions in case of non-linear optimization problems, and to design other semi-batch precipitation processes.

\section{References}

1. Zauner, R., Jones, A. G., Scale-up of continuous and semibatch precipitation processes, Ind. Eng. Chem. Res. 39 (2000) 239.

doi: https://doi.org/10.1021/ie990431u

2. Jones, A., Rigopoulos, S., Zauner, R., Crystallization and precipitation engineering, Comput. Chem. Eng. 29 (2005) 1159.

doi: https://doi.org/10.1016/j.compchemeng.2005.02.022

3. Costa, R., Moggridge, G. D., Saraiva, P. M., Chemical product engineering: An emerging paradigm within chemical engineering, AIChE J. 52 (2006) 1976. doi: https://doi.org/10.1002/aic.10880

4. Siener, R., Bangen, U., Sidhu, H., Honow, R., von Unruh, $G$., Hesse, A., The role of oxalobacter formigenes colonization in calcium oxalate stone disease, Kidney Int. 83 (2013) 1144

doi: https://doi.org/10.1038/ki.2013.104
5. Ivanovski, O., Drueke, T. B., A new era in the treatment of calcium oxalate stones? Kidney Int. 83 (2013) 998. doi: https://doi.org/10.1038/ki.2013.41

6. Grohe, B., Rogers, K. A., Goldberg, H. A., Hunter, G. K. Crystallization kinetics of calcium oxalate hydrates studied by scanning confocal interference microscopy, J. Cryst. Growth 295 (2006) 148. doi: https://doi.org/10.1016/j.jcrysgro.2006.07.029

7. Nielsen, A. E., The kinetics of calcium oxalate precipitation, Acta Chem. Scand. 14 (1960) 654 doi: https://doi.org/10.3891/acta.chem.scand.14-1654

8. Garside, J., Brecevic, L., Mullin, J. W., The effect of temperature on the precipitation of calcium oxalate, J. Cryst. Growth 57 (1982) 233. doi: https://doi.org/10.1016/0022-0248(82)90478-X

9. Brecevic, L., Kralj, D., Garside, J., Factors influencing the distribution of hydrates in calcium oxalate precipitation, J. Cryst. Growth 97 (1989) 460. doi: https://doi.org/10.1016/0022-0248(89)90227-3

10. Houcine, I., Plasari, E., David, R., Villermaux, J., Influence of mixing characteristics on the quality and size of precipitated calcium oxalate in a pilot scale reactor, Chem. Eng. Res. Des. 75 (1997) 252. doi: https://doi.org/10.1205/026387697523534

11. Grases, F., Millan, A., Conte, A., Production of calcium oxalate monohydrate, dihydrate or trihydrate - A comparative study, Urol. Res. 18 (1990) 17. doi: https://doi.org/10.1007/BF00294575

12. Sohnel, O., Garside, J., Kinetics of Precipitation, in: Precipitation- Basic Principles and Industrial Application, Butterworth-Heinemann, U.K., 1992, pp. 112.

13. Hulburt, H. M., Katz, S., Some problems in particle technology, Chem. Eng. Sci. 19 (1964) 555. doi: https://doi.org/10.1016/0009-2509(64)85047-8

14. Randolph, A. D., Larson, M. A., Theory of particulate processes, analysis and techniques of continuous crystallization, Academic Press, London, 1971.

15. Myerson, A. S., Handbook of industrial crystallization, Butterworth-Heinemann, Boston, 2002

16. Heinrich, J., Ph.D. Thesis, Determination of crystallization kinetics using insitu measurement techniques and modelbased experimental design and analysis, Martin Luther University, Wittenberg, Germany, 2008.

17. Hatakka, H., Ph.D. Thesis, Effect of hydrodynamics on modelling, monitoring and control of crystallization, Lappeenranta University, Finland,2010.

18. Ramkrishna, D., Population Balances: Theory and Applications to Particulate Systems in Engineering, Academic Press Inc, London, 2000.

19. Ramkrishna, D., The status of population balances, Rev. Chem. Eng. 3 (1985) 49 doi: https://doi.org/10.1515/REVCE.1985.3.1.49

20. Iggland, M., Mazzotti, M., Population balance modeling with size-dependent solubility: Ostwald ripening, Cryst. Growth Des. 12 (2012) 1489. doi: https://doi.org/10.1021/cg201571n

21. Braatz, R. D., Advanced control of crystallization processes, Annual Reviews in Control 26 (2002) 87. doi: https://doi.org/10.1016/S1367-5788(02)80016-5

22. Barrasso, D., Oka, S., Muliadi, A., Litster, J. D., Wassgren, $C$., Ramachandran, $R$., Population balance model validation and prediction of CQAs for continuous milling processes: toward $\mathrm{QbD}$ in pharmaceutical drug product manufacturing, J. Pharm. Innov. 8 (2013) 147. doi: https://doi.org/10.1007/s12247-013-9155-0 
23. Kumar, S., Ramkrishna, D., On the solution of population balance equations by discretization-I. A fixed pivot technique, Chem. Eng. Sci. 51 (1996) 1311. doi: https://doi.org/10.1016/0009-2509(96)88489-2

24. Marchal, P., David, R., Klein, J. P., Villermaux, J., Crystallization and precipitation engineering-I. An efficient method for solving population balance in crystallization with agglomeration, Chem. Eng. Sci. 43 (1988) 59. doi: https://doi.org/10.1016/0009-2509(88)87126-4

25. Costa, C. B. B., Maciel, M. R. W., Filho, R. M., Considerations on the crystallization modeling: Population balance solution, Comput. Chem. Eng. 31 (2007) 206. doi: https://doi.org/10.1016/j.compchemeng.2006.06.005

26. Zauner, R., Jones, A. G., Mixing effects on product particle characteristics from semi-batch crystal precipitation, Trans IChemE 78 (2000) 894. doi: https://doi.org/10.1205/026387600527969

27. Sarkar, D., Rohani, S., Jutan, A., Multi-objective optimization of seeded batch crystallization processes, Chem. Eng. Sci. 61 (2006) 5282. doi: https://doi.org/10.1016/j.ces.2006.03.055

28. Mullin, J. W., Crystallization, Fourth Ed., ButterworthHeinemann, London, 2001.

29. Alatalo, H., Hatakka, H., Kohonen, J., Reinikainen, S., Louhi-kultanen, M., Process control and monitoring of reactive crystallization of L-glutamic acid, AIChE J. 56 (2010) 2063.

30. Bernard-Michel, B., Pons, M., Vivier, H., Rohani, S., The study of calcium oxalate precipitation using image analysis, Chem. Eng. J. 75 (1999) 93. doi: https://doi.org/10.1016/S1385-8947(99)00077-7
31. Blandin, A. F., Mangin, D., Nallet, V., Klein, J. P., Bossoutrot, J. M., Kinetics identification of salicylic acid precipitation through experiments in a batch stirred vessel and a T-mixer, Chem. Eng. J. 81 (2001) 91. doi: https://doi.org/10.1016/S1385-8947(00)00227-8

32. Wang, $Y$., $M a, S$., Lu, X., Xie, C., Control of the agglomeration of crystals in the reactive crystallization of 5-(difluoromethoxy)-2-mercapto-1H-benzimidazole, Front. Chem. Sci. Eng. 6 (2012) 423. doi: https://doi.org/10.1007/s11705-012-1211-7

33. Bramley, A. S., Hounslow, M. J., Ryalls, R. L., Aggregation during precipitation from solution, Kinetics for calcium oxalate monohydrate, Chem. Eng. Sci. 52 (1997) 747. doi: https://doi.org/10.1016/S0009-2509(96)00447-2

34. Aamir, E., Nagy, Z. K., Rielly, C. D., Kleinert, T., Judat, B., Combined quadrature method of moments and method of characteristics approach for efficient solution of population balance models for dynamic modeling and crystal size distribution control of crystallization processes, Ind. Eng. Chem. Res. 48 (2009) 8575. doi: https://doi.org/10.1021/ie900430t

35. Baldyga, J., Podgorska, W., Pohorecki, R., Mixing-precipitation model with application to double feed semibatch precipitation, Chem. Eng. Sci. 50 (1995) 1281. doi: https://doi.org/10.1016/0009-2509(95)98841-2

36. Lindenberg, C., Mazzotti, M., Continuous precipitation of L-asparagine monohydrate in a micromixer: estimation of nucleation and growth kinetics, AIChE J. 57 (2011) 42. doi: https://doi.org/10.1002/aic.12326 